ISSN: $1130-3743$ - e-ISSN: 2386-5660

DOI: http://dx.doi.org/10.14201/teoredu3017594

\title{
LA PEDAGOGÍA LIGERA EN TIEMPOS HIPERMODERNOS: EL HOMESCHOOLING, LAS ESCUELAS WALDORF Y LA NUEVA PEDAGOGÍA IGNACIANA
}

Light pedagogy in hypermodern times: the homeschooling, the Waldorf schools, and the new ignatian pedagogy

La pédagogie légère en temps hypermodernes: le homeschooling, les écoles Waldorf, et la nouvelle pédagogie ignatienne

Jon Igelmo-Zaldivar* y Patricia Quiroga UCEDA**

* Universidad Complutense de Madrid. Facultad de Educación. Departamento de Didáctica y Teoría de la Educación. c/ Rector Villanova, s/n. 28040 Madrid. jigelmoz@ucm.es

* Universidad Nacional de Educación a Distancia. Facultad de Educación. Departamento de Historia de la Educación y Educación Comparada. c/Juan del Rosal, 14.28040Madrid.pquiroga@edu.uned.es

Fecha de recepción: enero de 2018

Fecha de aceptación: marzo de 2018

RESUMEN

El conjunto de la obra de Gilles Lipovetsky es una referencia para el análisis de las sociedades hipermodernas. En su último libro, titulado De la ligereza (2016), el autor francés estudia del paradigma sobre el que se está constituyendo la civilización de lo ligero. Un planteamiento que posee implicaciones en el campo de la educación. En este artículo analizamos, en primer lugar, las posibilidades teóricas que la contraposición de lo ligero y lo pesado posee para la reflexión pedagógica. 
En segundo lugar, con el fin de ahondar en el análisis, nos centramos en el estudio de tres propuestas educativas que integran nociones centrales de lo que podría considerarse una pedagogía ligera y que están experimentando una creciente demanda de su propuesta educativa: a) homeschooling, unschooling y flexi-schooling, b) la pedagogía Waldorf y c) las escuelas jesuitas catalanas que participan del proyecto Horitzó 2020.

Palabras clave: Gilles Lipovetsky; pedagogía ligera; bomeschooling; pedagogía Waldorf; pedagogía ignaciana.

\section{SUMMARY}

Gilles Lipovetisky's work is a reference to analyze the hypermodern societies. In his last book entitled De la ligereza (2016) the French author studies the paradigm sustaining a civilization based on the notion of lightness. This approach contains implications in the field of education. In this paper we analyze first of all the theoretical possibilities of counterpoising the heaviness and the lightness to encourage the pedagogical thinking. On the other hand, in order to delve into the analysis, we focus on three educative proposals integrating central notions of the light pedagogy which are undergoing a growing demand of their educative proposal: a) homeschooling, unschooling and flexi-schooling, b) Waldorf education, and c) Catalan Jesuit schools participating in the project Horitzó 2020.

Key words: Gilles Lipovetsky; light pedagogy; homeschooling; Waldorf Pedagogy; ignatian pedagogy.

\section{SOMMAIRE}

Le travail de Gilles Lipovetsky est une référence exceptionnelle pour l'analyse des sociétés hypermodernes. Dans son dernier livre intitulé De la légèreté (2016) l'auteur français présente une étude détaillée du paradigme sur lequel est en train de devenir la civilisation du légère. Une approche qui a des implications dans le domaine de la pédagogie et de l'éducation. Dans cet article, nous analysons d'abord les possibilités théoriques que le contraste entre la légèreté et la lourdeur a pour la réflexion pédagogique aujourd'hui. Deuxièmement, afin d'approfondir l'analyse, nous nous concentrons sur l'étude de trois propositions éducatives tout en intégrant des notions centrales de ce qui pourrait être considéré comme une pédagogie légère, connaissent une demande croissante de sa proposition éducative: a) bomeschooling, unschooling et flexischooling, b) la pédagogie Waldorf et c) les écoles catalanes jésuites participant au projet Horitzó 2020.

Mots clés: Gilles Lipovetsky; pédagogie légère; homeschooling; pédagogie Waldorf; pédagogie ignatienne. 


\section{INTRODUCCIÓN}

El 14 de noviembre de 2016 en la ponencia presentada en el Seminario Interdisciplinario de Teoría de la Educación (SITE) celebrado en Vic, Enric Prats, Luis Nuñez, Patricia Villamor y Silvana Longueira señalaban que "Las primeras décadas del siglo Xxi están atestiguando la emergencia de propuestas educativas que, aparentemente, vienen a modificar los puntos de anclaje pedagógico del último tercio del siglo XX» (2016, 21). Se hacía énfasis en este trabajo en la consolidación de una diversidad creciente de propuestas educativas -categorizadas como pedagogías emergentes por los autores de la ponencia- que con una fuerza notable están desafiando tanto el relato como el discurso predominante que ha sostenido a las instituciones educativas en los últimos cuarenta años. Un primer análisis general de este fenómeno implica observar el modo en que el desarrollo de complejas tecnologías y herramientas digitales (Bernal, 2009), la crisis del capitalismo especulativo neoliberal (Verger y Bonal, 2009), el auge de dispositivos de la biopolítica educativa (Bárcena, Pagni y Gelamo, 2013; Saura y Luengo, 2015) y las dificultades que presentan las democracias representativas para dar respuesta a los anhelos participativos de la ciudadanía tras la Segunda Guerra Mundial (Greene, 1994) configuran el contexto del que emergen un conjunto significativo de propuestas pedagógicas plurales y periféricas.

En el intento por estudiar este fenómeno, desde la teoría de la educación se sigue la lógica basada en a) encontrar un término con cierto significado en la historia reciente de la educación, b) acotar epistemológicamente un concepto en función de una serie de convenciones lingüísticas contemporáneas que (re)cargan de contenido el concepto en cuestión y c) establecer un listado de acciones pedagógicas que al cumplir con unas determinadas características pueden ser agrupadas bajo ese concepto. Es así como la noción de pedagogías emergentes ha irrumpido recientemente en el lenguaje de la teoría de la educación. Una aproximación teórica que ha dado en los últimos años importantes resultados y lo sigue haciendo. No obstante, en este artículo nos desmarcamos explícitamente de esta lógica teórica.

Partimos para nuestro análisis de que los cambios que se están produciendo en materia pedagógica, y que presentan un escenario educativo caracterizado por una pluralidad de opciones formativas, responden a las condiciones de posibilidad que presenta el imaginario social contemporáneo. Por imaginario social entendemos, siguiendo al filósofo canadiense Charles Taylor, la forma en que las personas «imaginan su existencia social, el tipo de relaciones que mantienen con otras, el tipo de cosas que ocurren entre ellas, las expectativas que se cumplen habitualmente y las imágenes e ideas normativas más profundas que subyacen a estas expectativas» (Taylor, 2002, 107). A nivel analítico, los imaginarios demandan de categorías específicas más cercanas a las metáforas que a los conceptos. Lo imaginario no responde a ideas, identidades o imágenes con los contornos bien definidos o acotados. Siguiendo a Emanuel Lizcano, el imaginario es el lugar de donde emergen las representaciones y las categorías y donde los conceptos se hallan pre-tensados. 
De tal forma, «la metáfora es esa tensión entre dos significados, ese percibir el uno como si fuera el otro, pero sin acabar de serlo» (Lizcano, 2006, 61). Dicho de otra forma, al poner el centro de atención en el imaginario social se observa que debajo de cada concepto late una metáfora que en parte ha olvidado lo que es. Siendo ese olvido el que «da consistencia a nuestros conocimientos, a nuestros conceptos e ideas» (Lizcano, 2006, 61). Lo que proponemos, por tanto, en este artículo es tomar como referencia para analizar los cambios pedagógicos contemporáneos la contraposición metafórica entre lo ligero y lo pesado desarrollada en su último libro por Gilles Lipovetsky, titulado precisamente De la ligereza (2016). Con este ejercicio buscamos abrir un frente de estudio de lo que está aconteciendo en el campo de la práctica educativa en el contexto de las sociedades hipermodernas, al tiempo que abandonamos la pretensión de buscar nuevos términos a partir de los cuales clasificar la «realidad pedagógica».

\section{LO LIGERO Y LO PESADO EN LA CONSTITUCIÓN DE LAS SOCIEDADES HIPERMODERNAS}

Tomando como referencia la obra de Lipovetsky, las sociedades hipermodernas son aquellas en las que los individuos «están a la vez más informados y más desestructurados, son más adultos y más inestables, están menos ideologizados y son más deudores de las modas, son más abiertos y más influenciados, más críticos y más superficiales, más escépticos y menos profundos» (Lipovetsky y Charles, 2006, 29). El estudio de las sociedades hipermodernas recorre la bibliografía del pensador francés. Ya en su libro La era del vacío de 1983 eran objeto de estudio las características que definen la vida organizada de los individuos en la segunda mitad del siglo xx: el hedonismo, la descomposición de las estructuras que dan sentido a la vida en sociedad, el consumismo como ideología, la recomposición de la relación sociedad e individuo o la nueva axiología de las democracias liberales capitalistas tras la Segunda Guerra Mundial. Todo lo cual conforma una revolución individualista que responde a un proceso de personalización que «ha promovido y encarnado masivamente un valor fundamental, el de la realización personal, el respeto a la singularidad subjetiva, a la personalidad incomparable sean cuales sean por lo demás las nuevas formas de control y de homogeneización que se realizan simultáneamente» (Lipovetsky, 1986, 7).

Es importante identificar la distancia tácita que presenta la obra de Lipovetsky con otros muchos autores que han centrado sus análisis de las sociedades occidentales y el pensamiento contemporáneo desde la perspectiva de la postmodernidad. La introducción de la noción de hipermodernidad, en última instancia, pone de manifiesto el intento por marcar distancia respecto a la conceptualización predominante en clave postmoderna de las décadas finales del siglo xx y las primeras del xxI. Un concepto que es capaz de aglutinar en su definición los tres grandes ejes sobre los que pivotan las estructuras propias de las sociedades liberales: «El movimiento, la fluidez, la flexibilidad" (Lipovertsky y Charles, 2006, 27). Las sociedades hipermodernas, para el autor francés, no se constituyen como resultado de 
un enfrentamiento directo con la modernidad; tampoco lo hacen como un intento de superar las estructuras modernas. Más bien, y en esto coincide con autores como Jean-François Lyotard (1994) y Antonio Campillo (1985), la hipermodernidad encuentra su fundamento en el proceso de agotamiento de la modernidad. Desde esta perspectiva, como ya señalaron pensadores como Gianni Vattimo (1985), el nuevo tiempo que se abre más allá de la modernidad "se caracteriza por una indiferencia, una resignación generalizada, un "pensamiento débil"» (Moret, 2012, 346).

El punto de partida de Lipovetsky en su último libro, titulado De la ligereza, es el siguiente: "Está en marcha una dinámica dotada de una fuerza poderosísima que construye una civilización de nuevo cuño: la civilización de lo ligero» (2016, 13). Lipovetsky interpela al lector ofreciendo en su libro un camino metafórico para explicar el modo en que las lógicas estructurales de la modernidad -la racionalización, la diferenciación funcional, la individualización, la secularización o la mercantilización del mundo- están sufriendo importantes variaciones en las últimas décadas. Este camino es el de la contraposición de lo ligero y lo pesado. La ligereza se posiciona como un ideal predominante en las sociedades hipermodernas. El arte, la economía, el cuerpo, la tecnología, la moda, la arquitectura y los sentimientos no son ajenos a este cambio de paradigma. Aunque lo pesado, lejos de desaparecer o difuminarse, encuentra su espacio en la existencia de los individuos que habitan e imaginan el mundo en Occidente. De tal manera, "hemos ganado mucho en ligereza para obrar, pero muy poco en ligereza interior», lo que implica que «nuestro universo social y cultural quiere ser ligero, pero el ciudadano no lo es» (Lipovetsky, 2016, 335).

Siguiendo lo expuesto por Lipovetsky, aunque «este nuevo empuje por lo ligero es un fenómeno único en la historia. Sin embargo, no ha sido desconocido por ninguna civilización» (ibíd., 15). Los intentos por generar espacios y tiempos para aligerar la pesada existencia tienen un fundamento antropológico. No hay cultura sin espacios y tiempos propios para la suspensión y la profanación de la monotonía y las inclemencias de la vida diaria y sus rituales. Si bien "la lucha de lo ligero contra lo pesado cruza su umbral decisivo desde mediados del siglo xx con la aparición de la economía de consumo» (ibíd., 26), es en la segunda mitad del siglo xx cuando se representa la variación o recreación, siguiendo las tesis de Campillo, entre lo moderno y lo hipermoderno (1985, 94). Un tiempo en el que aparece ya configurada la "sociedad moderna líquida», que es aquella en la que "las condiciones sobre las que sus miembros actúan cambian más rápido que lo que tardan en consolidarse en hábitos y rutinas» (Bauman, 2005, 1). Para Lipovetsky, en este umbral histórico la economía de consumo se posiciona en un lugar preferente en el marco explicativo de la predominancia de la ligereza. A partir de los años cincuenta y sesenta en los países desarrollados el consumismo «no deja de multiplicar las ofertas de confort, de desarrollar las facilidades, comodidades y atractivos del bienestar material» (Lipovetsky, 2016, 26).

La medida en que la pedagogía está inmersa en este proceso de recreación entre lo moderno y lo hipermoderno, y, por tanto, sujeta a la contraposición de 
modelos ligeros y pesados, resulta de interés desde la perspectiva de la teoría de la educación. Apenas en el último capítulo del libro De la ligereza, Lipovetsky dedica unos pocos párrafos a la problemática educativa en función del análisis que posibilitan las metáforas de lo ligero y lo pesado:

Los métodos docentes, ya lo sabemos, se basan en los valores del esfuerzo y la disciplina, en la lentitud y el avance controlado, en ejercicios repetitivos y programas impuestos con vistas a una adquisición de tipo sistemático. En el extremo opuesto, la cultura interactiva de la pantalla hace prevalecer lo lúdico, lo rápido, el azar, lo fragmentado, la ausencia de cauces y de linealidad. Es evidente que hay una relación antagónica entre las prácticas de la Red y las exigidas por la Enseñanza. Y el resultado de las primeras, además, es que descalifican a las segundas, las vuelven «anticuadas» y más plomizas que nunca. Mientras la cultura digital permite un acceso más fácil al conocimiento, transforma a los profesores en dinosaurios y vuelve cada vez más pesadas las vías clásicas de la transmisión del saber. En la era hipermoderna, vemos otro ejemplo de la guerra de lo ligero contra lo pesado en un nuevo territorio: la adquisición de conocimientos (2016, 322).

Entrado el siglo xxi la pedagogía pone en evidencia su descuidada pesadez en un contexto donde la ligereza se manifiesta también en los espacios educativos como un ideal en sí mismo. Es cierto que existen corrientes de pensamiento pedagógico que han contribuido notablemente a aligerar la educación liberando del pecado original al sujeto que aprende -Rousseau, Pestalozzi, Herbart-, apostando por materiales pedagógicos menos pesados para los niños y niñas -Fröbel, Pikler- o liberando los cuerpos de los estudiantes -Ferrière, Neill-, repensando los espacios escolares -Giner de los Ríos, Montessori-, cuyo reflejo es visible en numerosas escuelas e instituciones educativas. De igual manera se puede constatar que más allá de los desarrollos teóricos de estos pedagogos el común general de las instituciones educativas contrasta en los tiempos ligeros contemporáneos por el desarrollo de un modelo de educación pesada. El día a día de las escuelas infantiles, colegios e institutos queda supeditado a la obligación de asimilar unos contenidos determinados, ejecución de protocolos de evaluación precisos referentes a competencias genéricas y específicas, la autoridad del maestro o maestra, el espacio del aula escolar y el libro de texto. La predominancia que el informe PISA, con su lenguaje expertocrático (Tröhler, 2013), tiene en el diseño de las políticas educativas de los países occidentales es la principal prueba de la pesadez que envuelve a la educación contemporánea.

El problema del anclaje de la pedagogía ligera, en última instancia, conlleva discutir la parte pesada de la educación a la que no es posible renunciar. Así, al tiempo que se asume que el tránsito hacia lo ligero es inevitable y que la enseñanza de antaño no volverá, resulta ilusorio, según Lipovetsky, "creer que las cabriolas en las redes, el autodidactismo y otras actividades lúdicas y personales bastan para formar espíritus estructurados» (2016, 324). Pensamos, por tanto, quienes firmamos este trabajo, que uno de los retos que deberá asumir la teoría de la educación en los próximos años es la discusión sobre los mínimos de formación pesada a la 
que no es posible renunciar. Un análisis de fundamento ontológico que debe ser considerado una prioridad en la medida en que en el contexto de la hipermodernidad tienen sentido las instituciones educativas y las prácticas pedagógicas. Un problema que ya ha sido explorado por autores como Jan Masschelein y Maarten Simons en su libro En Defensa de la Escuela: una cuestión pública (2014). Pues como nos recuerda Lipovetsky «Es necesario mirar de frente los límites y los fracasos del paradigma de la ligereza, aplicado a la esfera educativa. [...] No hay educación digna de este nombre sin el peso de todo un conjunto de imposiciones, de transmisión institucionalizada» (2016, 326).

Consideramos para el análisis que presentamos que la contraposición de lo ligero y lo pesado en el campo de la educación permite analizar al menos tres propuestas pedagógicas que están experimentando una creciente demanda en la actualidad. El estudio de las mismas, desde nuestra perspectiva, supone un ejercicio de anticipación del escenario pedagógico que en las próximas décadas puede posicionar a estas propuestas como hegemónicas. En primer lugar, abordaremos la cuestión de las familias que rechazan escolarizar a sus hijos e hijas y apuestan por el homeschooling, flexi-schooling o unschooling como modelos preferentes. En segundo término, siguiendo la lógica de lo ligero y lo pesado propuesta por Lipovetsky, centramos nuestra atención en la demanda de las escuelas de fundamentación esotérica, nos referimos a las escuelas Waldorf, que crecen exponencialmente y que ofertan una educación para «espíritus ligeros». Finalmente analizamos el tránsito hacia pedagogías ligeras que está siendo llevado a cabo por congregaciones religiosas católicas que hasta hace apenas unos años eran consideradas las salvaguardas de la pedagogía pesada. Ponemos especial atención en esta tercera línea en el caso de los colegios de los jesuitas catalanes que han emprendido un particular proceso de innovación pedagógica, proyecto conocido como Horitzó 2020 , en búsqueda de la excelencia académica. Según nuestro criterio, las tres propuestas pedagógicas seleccionadas definen la antesala práctica de lo que bien podría denominarse el imaginario pedagógico hipermoderno.

\section{EL HOMESCHOOLING, EL UNSCHOOLING Y EL FLEXI-SCHOOLING: UNA CRÍTICA FRONTAL A} LAS INSTITUCIONES EDUCATIVAS PESADAS

En el último informe de la Office of Non-Public Education (ONPE) del U.S. Department of Education, se presentaron las siguientes cifras: «En la primavera de 2011, un número estimado de 1,77 millones (1.770.000) de estudiantes practicaron bomeschooling en los Estados Unidos [...] el porcentaje estimado de población en edad de escolarización que practicó homeschooling incrementó en 2.9 puntos porcentuales en 2007 y en 3.4 en 2011». Estas cifras permiten contrastar el desgaste que presentan las instituciones educativas en las sociedades hipermodernas. Es importante mencionar que los estudios presentados por Michael Apple (2000) o Moralee Mayberry (1988) hace más de veinte años sobre la educación en casa, y que vinculaba casi en su totalidad esta práctica pedagógica con los movimientos 
fundamentalistas norteamericanos, no responden en la actualidad a un fenómeno pedagógico que ha incrementado su complejidad y diversidad en las dos últimas décadas. Autores como Collom ya han señalado que «la nueva generación de homeschoolers tiene una base lógica diferente» $(2005,331)$ y que no se fundamenta exclusivamente en motivos de índole religiosa.

Por lo tanto, un hecho es que la decisión de rechazar la escolarización crece paulatinamente en los países económicamente más desarrollados del mundo en las últimas cuatro décadas. De forma paralela, crecen en su diversidad los argumentos que llevan a las familias a optar por este rechazo a la escolarización. Lo cierto es que en los contextos donde el consumo se ha ido posicionado como un ideal axial dentro del imaginario social predominante, la diversidad de modos de educarse y aprender se incrementa y las posibilidades de uso de las instituciones educativas se ensancha. La educación es un servicio que se consume si el consumidor lo desea. La frontera entre el consumo de bienes y servicios que fue estudiada por el Club de Roma en su informe The Limits to Growth de 1972 se ha difuminado considerablemente con independencia de si el servicio lo ofrece el Estado, una multinacional, una cooperativa vecinal o una congregación religiosa. Todo lo cual implica, como señala Lipovetsky, una nueva relación con el saber y la autoridad de la que emana el conocimiento:

La revolución de lo ligero ha llevado a crear una relación inédita con el saber, así como nuevos modos de adquisición de conocimientos. Hasta hace poco, la transmisión de la "cultura" se efectuaba a través de determinadas instituciones centrales de la sociedad: las tradiciones, la familia, la Iglesia, la Enseñanza [...] Estamos en un momento en el que segmentos enteros de lo que sabemos escapan al control de las autoridades institucionalizadas, dado que se basan en trayectorias personales, en prácticas individuales que dependen de la necesidad, en andaduras aleatorias propias de cada cual. Con la revolución de lo ligero, la adquisición de saber tiende a desembarazarse del peso de los contextos colectivos pesados, de las mediaciones tradicionalmente dedicadas a este fin $(2016,321)$.

No debe extrañar, por tanto, que no pocos de quienes buscan fundamentar las prácticas educativas contemporáneas basadas en el homeschooling, unschooling o flexi-schooling encuentren en los teóricos radicales de la educación de los años 60 y 70 la base de los planteamientos pedagógicos más ligeros en relación con las pesadas instituciones educativas modernas. Baste mencionar que la continuidad entre las teorías de la desescolarización formuladas hace más de cuarenta años por pensadores como John Holt, Ivan Illich y Paul Goodman y el discurso pedagógico líquido ha sido analizada en función de «un mismo origen histórico y un mismo marco epistemológico» (Igelmo y Laudo, 2017). Así, en la búsqueda de elementos que ayuden a aligerar el peso de la educación que se imparte en las instituciones educativas, el discurso de autores como John Holt, padre intelectual del homeschooling (Igelmo, 2015), adquieren un nuevo significado: "Aparte de resultar aburrida, la escuela es casi siempre fea, inhóspita e inhumana» (Holt, 1977, 26). La escuela se presenta en su obra como un espacio varado en prácticas anticuadas, apenas maleable, inflexible en su esencia y que no atiende a los cambios 
que acontecen en el contexto social, económico, político y tecnológico. Lo que define a las instituciones educativas, según Holt, es la capacidad que poseen para imponer cierto orden. El pedagogo norteamericano, en su conocido libro El fracaso de la escuela, llega a señalar que «nuestras escuelas se aferran a la idea de que el aprendizaje en el aula es una consecuencia del orden» (Holt, 1977, 95). Una línea de argumentación que seguirá Illich en su libro Deschooling Society al denunciar con tono provocador que "la escuela es una agencia de publicidad que te hace creer que necesitas el orden social tal y como es» (1971, 113).

Por otro lado, no se puede obviar que el crecimiento cuantitativo que presentan en la última década los padres y madres que practican bomeschooling, unschooling o flexi-schooling está relacionado directamente con las posibilidades que ofrece Internet y las herramientas digitales contemporáneas. Como resultado de la consolidación de la versión 2.0 de la Red se observa un número destacado de propuestas pedagógicas que están desarrollando diversas formas de articular entornos y procesos de aprendizaje más flexibles. Lo que proponen quienes están explorando estas posibilidades pedagógicas digitales es la generación de entornos capaces de adaptarse a las necesidades, contextos culturales y gustos de cada individuo interesado en aprender. Aspectos todos ellos de gran calado en la contraposición pedagógica de lo ligero y lo pesado.

Siguen resultando contemporáneas las palabras escritas hace más de cincuenta años por Marshall McLuhan cuando señalaba que «este desafío (en relación al desafío tecnológico de los años cincuenta) ha destruido el monopolio del libro como ayuda a la enseñanza y ha derribado los propios muros de las aulas de modo tan repentino que estamos confundidos, desconcertados" (Carpenter y McLuhan, 1974, 235-236). En el contexto tecnológico del siglo XXI las instituciones educativas como consecuencia de su pesadez no solo no han podido adaptarse a un entorno cambiante que en las últimas décadas ha demandado instituciones más transparentes y dóciles, sino que además se muestran confundidas, torpes y desconcertadas. Las escuelas, pero también los centros de formación profesional y las universidades, se han replegado en un intento por salvaguardar su posición preferente en el plano social. O dicho en palabras de Paul Goodman, otro icono del pensamiento pedagógico crítico radical de los años sesenta, las instituciones educativas se han «recargado con una pompa y volumen poco acordes con la educación» (1970, 76). Todo lo cual nos devuelve, una vez más, al planteamiento de partida de Lipovetsky:

Algunos no ocultan su entusiasmo ante la potencialidad de Internet en la formación de los jóvenes, dado que en teoría tiene capacidad para favorecer la autonomía personal, la democratización del saber, un acceso a la cultura al margen del poder directivo de los docentes. De ahí la revitalización de la "sociedad sin escuela", antaño promovida por Ivan Illich y que hoy se ha vuelto realizable gracias a las proezas de la informática $(2016,323)$.

De tal forma, la educación en casa, basada en una crítica a la totalidad del pesado aparato institucional escolar, una crítica ya desarrollada hace cincuenta 
años por las teorías de la desescolarización, es concebida en la actualidad como una opción más entre otras para quienes piensan cómo organizar la educación de sus hijos e hijas. Las familias que optan por el homeschooling, el flexi-schooling o el unschooling buscan un modelo educativo en el que «el alumno puede avanzar, retroceder, ampliar, reducir, profundizar, investigar o pasar por encima de contenidos, según sus necesidades educativas específicas, bajo las orientaciones y la supervisión de sus padres o educadores» (Sotés, Urpí y Molinos, 2012, 65). El contexto digital que ha irrumpido en el campo de la educación en las dos últimas décadas refuerza la emergencia de esta práctica pedagógica. Es así como este modelo flexible, volátil, carente de referentes comunes y que rinde culto a la individualidad del educando se acopla con éxito a la demanda de estructuras ligeras para la formación en los tiempos hipermodernos.

\section{LA PEDAGOGÍA WALDORF: EDUCANDO A ESPÍRITUS LIGEROS}

Charlie Cetrine, el álter ego de Saul Bellow en la novela El legado de Humbolt de 1975, enfrenta todo tipo de calamidades en su día a día: problemas con Hacienda, denuncias de su exmujer, amenazas de la mafia, pérdida paulatina de su fortuna... Ante la pesadez de la existencia en las calles de Chicago, Cetrine, como hizo en su día también Bellow, encuentra en la antroposofía una puerta que da paso a un espacio donde prima la sensación de ligereza espiritual que marca distancia de la pesadez material del día a día. Cetrine-Below en una de las reflexiones introspectivas que abundan en la novela dice: «La antroposofía estaba produciendo efectos claros. No podía tomarme nada de aquello demasiado mal. Un aire de otro mundo lo teñía todo y cada poco mi espíritu se disociaba de mi cuerpo» (Bellow, 2016, 246). Es conocida, asimismo, la defensa que el premio nobel de literatura en 1976 hizo de la pedagogía que emanaba de la antroposofía: "Si tuviera un hijo en edad escolar, le enviaría a una escuela Waldorf” (Bellow, 2016).

Los centros educativos Waldorf han crecido cuantitativamente desde una perspectiva internacional en paralelo a la expansión de las sociedades hipermodernas. No es casual que mientras que en 1956 existieran un total de 62 centros Waldorf en el mundo, en 1975 estas cifras se duplicaran (113). Y que para 1992 el número de escuelas se hubiera multiplicado por cinco alcanzando las 567 (Quiroga y Girard, 2015). En la actualidad existen aproximadamente 1843 jardines de infancia repartidos en más de 70 países del mundo y 1080 escuelas Waldorf en 64 países (Freunde der Erziehungskunst Rudolf Steiners, 2016). En este sentido, España no es una excepción. Pese a que la recepción de la pedagogía Waldorf tuvo lugar de un modo tardío con respecto a otros países europeos (Quiroga, 2015), la demanda de estas escuelas sigue en aumento año tras año (Asociación de Centros Educativos Waldorf-Steiner de España, 2016).

La pedagogía Waldorf se fundamenta en la corriente esotérica de la antroposofía que Rudolf Steiner creó en 1913 en Alemania (Lachman, 2007, 175). Las dos primeras décadas del siglo xx fueron el escenario histórico del cual emergió un 
amplísimo abanico de heterodoxias religiosas. La antroposofía fue presentada por Steiner como «un camino de conocimiento que pretende guiar lo espiritual en el ser humano a lo espiritual del universo" (Steiner, 1973). Entre las críticas a Steiner y su obra, se encuentra la tesis de haber fundado una nueva religión (Lachman, 2007, 196). Ante esta cuestión el líder de la antroposofía afirmaba que «la Ciencia Espiritual no quiere tener nada que ver con la fundación de una nueva religión o con dar lugar a la aparición de profetas o fundadores de sectas. La humanidad ha madurado; el tiempo de los profetas y de la fundación de religiones ha terminado» (Steiner, 1914). Steiner quiso desvincular la antroposofía de una noción de religión institucionalizada, aspirando más bien a «establecer un estado religioso de la vida anímica que nos lleve a Cristo como el ser que se encuentra en el centro de la vida religiosa" (ibid.). Lo cual posiciona a la antroposofía en la actualidad como una alternativa espiritual en un tiempo en el que "creer en Dios ya no es axiomático" (Taylor, 2007, 3) y donde la búsqueda de plenitud no implica "ser un creyente» (ibid., 7).

El creciente interés que suscita la antroposofía en su fundamento espiritual, pero también en su vertiente médica, agrícola o educativa, bien puede quedar enmarcado en el contexto denominado por Peter L. Berger de "pluralismo religioso" $(2014,27)$. La antroposofía, de tal forma, responde en las sociedades hipermodernas al fenómeno de la proliferación de "religiones a la carta", siguiendo el término acuñado por Lipovetsky (Lipovetsky, 2006, 98). En este contexto de pluralismo religioso el autor francés identifica la emergencia del «culto al mayor bienestar» que proporciona un estado de «ligereza interior». En su argumentación subraya que "ha llegado el momento de la "desintoxicación" pero también el de la meditación, el yoga, las técnicas de relajación, el feng-shui, el "mayor bienestar", en pocas palabras, el de todo aquello que nos permita "sentirnos bien física y espiritualmente" (Lipovetsky, 2016, 12).

Siguiendo con la contraposición en clave metafórica de lo pesado y lo ligero propuesta por Lipovetsky cabe señalar que la pedagogía Waldorf contiene un conjunto de prácticas fundamentadas en una espiritualidad ligera. Así, en los jardines de infancia Waldorf la actividad principal es el juego libre que se posiciona como una actividad pedagógica clave en el desarrollo divino-espiritual de los educandos (Quiroga e Igelmo, 2013). Para Steiner «cada persona es la expresión de un ser divino-espiritual que desciende de una existencia puramente anímico-espiritual y que evoluciona aquí en una existencia físico-corpórea entre el nacimiento y la muerte» (Steiner en Marshak, 1997, 35). La estructuración de una jornada en una escuela Waldorf responde a lo que Steiner consideró como la "correcta educación". Una educación que:

Ha de tener por objeto lograr que lo que se experimente en el plano físico se lleve e incorpore en las actividades a las que el alma espiritual o espíritu anímico se halla entregada desde el momento de dormirse hasta el de despertar. Como maestros y educadores nada podemos transmitirle al niño de los mundos superiores, pues lo que de ellos procede penetra en la conciencia cuando el hombre está dormido. Lo 
único que podemos hacer es aprovechar el tiempo que el niño pasa en el plano físico ocupándolo en actividades que paulatinamente pueda llevar al mundo espiritual, de donde habrá de fluirle la energía que le permita cumplir con su misión humana en la existencia terrestre (Steiner, 2014, 18-19).

El ejemplo más visible de la ligereza de la pedagogía Waldorf en la etapa de educación infantil lo constituye la exclusión de aprendizajes intelectivos. Ni siquiera el alfabeto se aprende en este tiempo -también denominado primer septenio-, pues Steiner consideraba que en esta etapa "si forzamos los poderes intelectuales del niño, detenemos el desarrollo corporal» (Steiner, 1923, 30). La educación primaria, o segundo septenio, también se caracteriza por implementar una pedagogía liviana. En primer lugar, cabe destacar que no todas las asignaturas se imparten al mismo tiempo, sino que se organizan en la denominada "clase principal» en períodos de inmersión de 3-4 semanas (Burnett et al, 2000, 33). Un ejemplo de la singularidad de la pedagogía Waldorf es que no se aplican exámenes periódicos al uso, ni se obliga a los estudiantes a retener de un modo mecánico cierta cantidad de contenidos. Más bien se asume como parte natural del proceso de aprendizaje el olvido y el recuerdo posterior, todo lo cual forma parte del denominado «olvido deliberado» (Schieren, 2012, 70), por el que se enseña de un modo pictórico, de forma abierta y haciendo uso de los conceptos de forma flexible.

Después de la clase principal, que suele durar aproximadamente dos horas, los educandos tienen un recreo. Finalizado el recreo se desarrollan materias más expansivas como tejer, pintar con acuarela, euritmia, música o el cuidado de un huerto. En la educación secundaria, aunque la carga intelectiva es mayor, se sigue trabajando por períodos de inmersión. Las materias expansivas abarcan cestería, confección de prendas de vestir, tejer, trabajo con cartón y encuadernación de libros, carpintería, trabajo del metal (cobre y hierro) y elaboración de máscaras y títeres, educación física, idiomas y música. A las clases de euritmia y teatro se les da continuidad en esta etapa (Rawson et al., 2000, 69-90).

El contrapunto de la ligereza de esta pedagogía se encuentra en la carga de trabajo que recae en los docentes, para quienes se trata más bien de una pedagogía pesada. En primer lugar, para acceder a un trabajo como maestro/a han de tener una formación en pedagogía Waldorf que es complementaria a la de los grados de educación de una Facultad de Educación y que según cada país puede oscilar entre los dos y los cuatro años -en España son tres años- (Quiroga, 2015). Asimismo, en estas escuelas se prima que un mismo docente acompañe a los alumnos y alumnas durante el mayor tiempo posible. En el caso de la educación primaria, en España el denominado "maestro o maestra principal» acompaña a su curso desde 1. ${ }^{\circ}$ a $6 .^{\circ}$ de primaria. Esto significa que el docente ha de aprender un currículum nuevo para cada año escolar y que este requiere del aprendizaje de un número importante de materias poco al uso, tales como trabajos manuales, construcción y horticultura, entre otros (Rawson et al., 2000, 57-68). Además, cada semana, en la tarde de los jueves, se lleva a cabo el denominado "claustro». Una reunión diseñada por el propio Steiner cuya intención era que estos encuentros se convirtieran en 
una «universidad viva de la Facultad de los Maestros - una academia de formación permanente-» (Steiner en Rawson, 2010, 29).

En la línea con lo expuesto por Saul Bellow, la antroposofía es una herramienta que proporciona un aire de otro mundo que tiñe todo y que permite que el espíritu se disocie del cuerpo en un ejercicio esotérico de ligereza. Quienes participan de la corriente esotérica pedagógica de las escuelas Waldorf, en claro crecimiento a nivel mundial, buscan aumentar la sensación de bienestar para sus hijos e hijas. La pedagogía Waldorf se posiciona como una opción para la formación de espíritus ligeros que han de convivir con la existencia pesada cuya pauta queda marcada por la burocracia moderna, las instituciones oficiales, el rechazo al mundo natural, la lógica cientificista, el progreso material o el consumo desenfrenado de bienes y servicios. Espíritus ligeros para una nueva espiritualidad plural en la que los grandes relatos religiosos evidencian cierta incapacidad de ganar seguidores en el contexto de la hipermodernidad por su insistencia en tradiciones y esquemas formativos de índole pesada.

\section{LOS JESUITAS Y LA LIBERACIÓN DE SU PESADA TRADICIÓN PEDAGÓGICA}

El 28 de marzo de 2015 el periódico El País publicó un texto escrito por Patricia Gosálvez con el siguiente titular: "Los jesuitas revolucionan el aula». La entradilla del reportaje era la siguiente: "Trabajo por proyectos, flexibilidad y aprendizaje autónomo en vez de exámenes, libros y clases magistrales. Tres colegios de la orden inician un cambio radical» (2015). En el reportaje, la directora pedagógica de uno de los centros, el Colegio Claver-Raimat de Lleida, explicaba el fundamento del nuevo modelo pedagógico del centro basado en que "los niños aprenden haciendo, son más autónomos, el trabajo es colaborativo, los profesores hacen preguntas, no dan respuestas..." (ibid.). Lo mencionado por la directora se enmarca en el modelo educativo que ha comenzado a aplicarse en el ciclo lectivo 2014/15 en tres escuelas jesuitas en las que convive el modelo escolar tradicional y el programa Horitzó 2020 (Ochoa de la Fuente, 2015). En función de lo expuesto en este reportaje del periódico El País, la ligereza pedagógica está marcando la pauta del modelo educativo de un colegio de la congregación que más ha contribuido en la historia de la pedagogía al desarrollo y fundamentación de una pedagogía pesada. Baste recordar que en el caso de España, con anterioridad al orden escolar decimonónico, como ha señalado Raimundo Cuesta, son los jesuitas «en la enseñanza secundaria [...] los que construyeron los principales usos y tradiciones sociales del sistema escolar moderno" (Cuesta, 2009, 24).

Unas semanas después, el 16 de abril de 2015, esta vez el periódico El Mundo centraba su interés en el colegio concertado El Clot de Barcelona. El título elegido para el reportaje era el siguiente: "Así se enseña sin asignaturas, sin libros de texto y sin exámenes». Olga R. Sanmartín, la periodista que firma el reportaje, describe lo que considera una pedagogía fundamentada en un «aprendizaje basado en trabajo cooperativo que huye de verdades absolutas y plantea preguntas abiertas» (2015). 
Un nuevo modelo, siguiendo a Lipovetsky, en el que "lo obligatorio y pesado se subvalora en beneficio de lo ligero, lo fácil, lo entretenido, lo informal» (2016, 321322). El interés del reportaje reside en la transición que la reportera describe de un modelo caduco a un modelo transgresor. Lo que lleva a Olga R. Sanmartín a hablar de una "especie de teología de la liberación" que bien podría ser una "pedagogía de la liberación» de fundamento revolucionario:

Los curas hicieron la revolución el pasado mes de septiembre. Se cargaron los libros de texto, la semana de exámenes finales y el tradicional esquema de asignaturas, derribaron los tabiques y tiraron a la basura las tarimas. Los viejos pupitres de color verde pálido fueron reemplazados por sillones chill out. Modernizaron todo, hasta los crucifijos. Ahora son de una madera nórdica y ha desaparecido de ellos la figura del cristo agonizante (ibid.).

En ambos reportajes periodísticos se encuentra una descripción de los cambios arquitectónicos y del diseño que envuelven las transformaciones que se están llevando a cabo en diferentes colegios de los jesuitas en Cataluña. Patricia Gosálvez en su reportaje escribe: "Los niños hablan y se mueven con libertad. Bajo enormes lámparas tubulares hay zonas comunes con sofás, pufs, o un jardín vertical que están construyendo ellos mismos» (2015). Predominan los espacios «amplios, luminosos, con color, pensados para desarrollar las capacidades de los niños y niñas que les dan vida", permitiendo que los niños se muevan "por el aula con tranquilidad y autonomía, conociendo cada uno de los espacios» (ibíd.). Son valorados los espacios flexibles y funcionales que facilitan «desarrollar diferentes actividades en el aula, de exploración y de manipulación, de juego, de compartir y de trabajar individualmente» (ibíd.). Por su parte, Olga R. Sanmartín hace constar que se han construido "clases de 120 metros cuadrados con paredes y puertas transparentes. Todo es diáfano, de colores alegres, y hay gradas» (2015).

La búsqueda de un diseño específico para la nueva pedagogía jesuítica se puede analizar a partir de las palabras de Lipovetsky cuando señala que «la arquitectura y el diseño no están fuera de esta dinámica: también ellos contribuyen a dar forma a la civilización de lo ligero" (2016, 228). La estética de la ligereza responde a los gustos dominantes de "consumidores ávidos de "práctica" y emociones sensibles» (2016, 240). Una estética que en el caso de la nueva pedagogía ignaciana catalana contrasta con el tradicional estilo jesuítico pesado y sobrecargado. Un estilo, el de la Compañía de Jesús, que históricamente se ha caracterizado por la monumentalidad y la combinación de ornamentos que transita de lo neoclásico a lo barroco y donde destacan obras eclécticas que condensan su estética propia. Todo lo cual marca un contraste evidente en relación con la estética hipermoderna donde «la intención del diseño ya no es tanto concebir símbolos que subrayen la modernidad como objetos que concilien lo funcional y las necesidades psicológicas y sensitivas de los consumidores» (Lipovetsky, 2016, 240-241). Un modelo de diseño funcional y sensitivo que es integrado en la conceptualización del aula escolar que se plantea desde el proyecto Horitzó 2020: 
Las aulas son espacios de aprendizaje que permiten interacciones diversas, también las interacciones necesarias entre los tutores y las que piden cierta tranquilidad entre los alumnos. Por estas razones también hemos incluido dentro mismo del aula dos pequeñas salas de trabajo polivalentes, insonorizadas y con cierres de cristal. Una sirve de sala de trabajo de los tres profesores del grupo-aula, y la otra de lugar de trabajo, intercambio y conversación de pequeños grupos (Aragay et al., 2016a, 47).

Esta opción estética renovadora y ligera de este grupo de colegios de la Compañía de Jesús en Cataluña establece una continuidad con el discurso pedagógico que fundamenta la práctica en el aula y que queda expuesto en la serie de cuadernos publicados en los que se definen las líneas pedagógicas principales del Horitzó 2020. En estas publicaciones se concretan los fundamentos teóricos que guían la pedagogía ignaciana catalana del siglo XxI y que suponen un vuelco extraordinario, o siguiendo sus propias palabras una «innovación disruptiva" (Aragay et al., 2015a, 25), en relación con la tradición pedagógica de la Compañía de Jesús. La apuesta por una pedagogía que incorpora las nociones de ligereza queda formulada en estos Cuadernos a modo de principio de acción para la práctica: «Necesitamos una flexibilización radical de los modelos mentales actuales, poniendo en cuestión creencias o mitos considerados inamovibles hasta el momento» (ibid., 25).

En el análisis detenido de este modelo, se observa que la atención de los educandos se capta por parte del docente a partir de la práctica lúdica significativa y no de la tediosa teoría donde abundan conceptos y técnicas memorísticas. Se potencia «el desarrollo de inteligencias múltiples dando al juego un lugar destacado en el proceso de enseñanza y aprendizaje» (Aragay et al., 2015b, 53). La conceptualización del sujeto que aprende se hace en los siguientes términos: "El alumno: es el centro del proceso de enseñanza y aprendizaje. Tiene un papel activo y protagonista, trabaja de forma individual y cooperativa con sus compañeros" (ibíd., 41). El vuelco respecto a la tradición pedagógica de la Compañía de Jesús se pone de manifiesto de forma explícita en los Cuadernos publicados desde el proyecto Horitzó 2020: "Si antes los tutores se habían convertido en bomberos que apagaban fuegos, ahora deben ser inspiradores que amplíen horizontes» (Aragay et al., 2016b, 49).

La diversión se integra en la pedagogía de los colegios jesuitas con el fin de tomar distancia del tedio y el sopor que emana de su propia tradición pedagógica densa y pesada. Para tal fin el educando debe ser constituido como un sujeto activo que habla, hace, toca, aplica, inventa y se divierte y que no pierde el tiempo y esfuerzos en escuchar, ver, tomar distancia, aburrirse o imitar. El diseño de los espacios y los objetos queda al servicio de la nueva y ligera pedagogía ignaciana. Todo indica, por tanto, que ni los propios jesuitas que desde 1599 han hecho de la Ratio Studiorum su seña de identidad para su apostolado educativo, entrado el siglo XXI, son ajenos a la lógica pedagógica hipermoderna. De lo que se trata, en definitiva, es de dejar a un lado las escenas pedagógicas narradas por Ramón Pérez de Ayala en su famosa novela A.M.D.G. (1910), en la que describe algunas de sus 
experiencias en las aulas de los jesuitas del Colegio de Gijón y que durante más de un siglo han alimentado una determinada concepción de la pedagogía ignaciana:

Toda la semana de ejercicios guardábamos riguroso silencio. No teníamos clase, leyendo sólo libros de piedad y meditación; cantábamos, sin órgano, preces y salmos, y escuchábamos tres prácticas diarias. El Pecado, la Muerte y el Juicio Final eran palabras que se cernían siempre sobre nosotros, como las aves que rodean la querencia de los muros y torreones del colegio (Pérez de Ayala, 1983, 103).

\section{CONClusiones}

Ha sido Xavier Laudo quien recientemente ha señalado que la pedagogía postmoderna es una pedagogía "con perspectiva global y voluntad de coherencia interna, donde la relatividad se propone como valor normativo" (Laudo, 2011, 55). Consideramos, en función de lo expuesto, que el imaginario pedagógico de la hipermodernidad contiene las condiciones de posibilidad para construir una teoría educativa con fundamento normativo. En este sentido, la discusión de si existe o no pedagogía sin intención normativa (Trilla, 2005, 293) se convierte en un callejón sin salida en el contexto de la hipermodernidad. La contraposición entre la pedagogía ligera y la pedagogía pesada pone de manifiesto las posibilidades de una pedagogía hipermoderna que, al tiempo que ubica como valor normativo la relatividad, busca prácticas más ligeras, flexibles y adaptables a la subjetividad del educando sin que por ello se renuncie categóricamente a conservar la parte pesada de la educación. Una búsqueda o exploración de lo ligero que carecería de sentido sin el reconocimiento tácito o explícito de lo pesado. De ahí que la identificación explícita de la parte pesada de la educación se posicione como uno de los retos centrales de la teoría de la educación en el contexto de la hipermodernidad. Un reto que rebasa las pretensiones de este trabajo.

En el análisis que hemos planteado de los modelos pedagógicos por la que están optando las familias que organizan la educación de sus hijos al margen de las instituciones educativas oficiales, las escuelas Waldorf y los colegios de los jesuitas en Cataluña en la segunda década del siglo xxI, se ha podido constatar lo señalado por Lipovetsky: «La adquisición de saber tiende a liberarse de la pesantez del esfuerzo, la aridez, la lentitud» $(2016,321)$. Se observa una tendencia a despojarse de un andamiaje institucional poco maleable en un contexto caracterizado por la sucesión de cambios profundos que afectan a los campos de la política, la economía, la tecnología, la cultura y lo social. Al tiempo que se aspira a alcanzar estados de bienestar que tomen distancia de la pesadez existencial que generan los sistemas hipermodernos como herederos de las sociedades industriales modernas y su materialismo fundacional. De ahí la emergencia no tanto de nuevas pedagogías sino de modelos pedagógicos donde lo arduo, lo tedioso, lo exigente es arrinconado para mayor ganancia del aprendizaje rápido, sencillo y eficaz. Siendo este el sedimento teórico de una nueva conceptualización de la experiencia pedagógica 
donde las prácticas que demandan tesón, esfuerzo y dedicación son apartadas sistemáticamente. Todo cual es coherente, en cierta forma, con un imaginario hipermoderno en el que según Luigi Amara:

Lo que califica como acontecimiento o noticia, aquello sobre lo cual vale la pena hablar, lo verdaderamente significativo, es siempre lo diferente, no lo habitual: atendemos lo que introduce una variación, no lo que establece una continuidad; los picos más pronunciados de una gráfica, no las fluctuaciones imperceptibles que dibujan su curva $(2012,25)$.

La pedagogía ligera, por tanto, se define por su apuesta constante por la variación. Variación de espacios para la educación -la escuela no puede ser el espacio acaparador de la educación, se dice desde quienes practican la educación en casa-, variación en los relatos religiosos que justifican los fines determinados del proceso formativo -postura defendida por las escuelas Waldorf- y variación también en una pedagogía que posiciona a la actividad como valor axial y que salta de una acción formativa a otra en una búsqueda constante de la experiencia educativa eficiente -los colegios jesuitas catalanes constituyen un buen ejemplo en este sentido-. La cuestión, por tanto, que debe ser analizada tomando como referencia el desarrollo de estas tres propuestas pedagógicas tiene que ver con las posibilidades de anclaje que presenta la pedagogía ligera en su apuesta decidida por la variación y donde la continuidad queda debilitada. Un problema que nos interpela de forma directa como individuos que convivimos en sociedades hipermodernas y como pedagogos que vemos desde la distancia el tiempo de los grandes relatos educativos. Es por eso que coincidimos con Max Van Manen cuando señala que «los propósitos pedagógicos son expresiones no solo de nuestras teorías filosóficas de la vida, sino también de quiénes y de qué somos, y de cómo de activa o reflexiva es nuestra actitud ante el mundo" (Van Manen, 2015, 39).

\section{REFERENCIAS BIBLIOGRÁFICAS}

Amara, L. (2012) La escuela del aburrimiento. Barcelona, Sexto Piso.

Apple, M. (2000) Away with All Teachers: the cultural politics of home schooling. International Studies in Sociology of Education, 10 (1), 61-80. doi: 10.1080/09620210000200049.

Aragay, X.; Arnó, J.; Borrás, P.; Iniesta, D.; Menéndez, P.; Riera, P.; Tarín, L. e Ylla, L. (2015a) Enfocamos el objetivo. 40 consideraciones para el cambio educativo. Cuaderno 1. Consultado el 7 de noviembre de 2016. http://h2020.fje.edu/es/quaderns/Q1-CAST.pdf.

Aragay, X.; Arnó, J.; Borrás, P.; Iniesta, D.; Menéndez, P.; Riera, P.; Tarín, L. e Ylla, L. (2015b) Pasamos a la acción. 35 pasos para vivir el cambio educativo. Cuaderno 4. Consultado el 7 de noviembre de 2016. http://h2020.fje.edu/es/quaderns/Q4-CAST

Aragay, X.; Arnó, J.; Borrás, P.; Iniesta, D.; Menéndez, P.; Riera, P.; Tarín, L. e Ylla, L. (2016a) Rediseñamos los espacios de la escuela. 35 escenarios para trazar el cambio educativo. Cuaderno 7. Consultado el 7 de noviembre de 2016. http://h2020.fje.edu/ es/quaderns/Q7-CAST-redisenamos-los-espacios.pdf. 
Aragay, X.; Arnó, J.; Borrás, P.; Iniesta, D.; Menéndez, P.; Riera, P.; Tarín, L. e Ylla, L. (2016b) Catamos el sueño. 32 experiencias para vivir el cambio educativo. Cuaderno 8. Consultado el 7 de noviembre de 2016. http://h2020.fje.edu/es/quaderns/Q8-CASTcatamos-el-sueno.pdf

Asociación de Centros EduCATivos Waldorf-STEINER DE EsPaÑa (2016) Centros educativos Waldorf. Revista Waldorf-Steiner Educación, 25, 3-7.

Bárcena Orbe, F.; Pagni, P. A. y Gelamo, R. P. (2013) Educación, experiencia y pedagogía biopolítica, por un diagnóstico de nuestro presente educacional. Revista Sul-Americana de Filosofía e Educação, 20 (2), 87-116

Bauman, Z. (2005) Liquid Life. Cambridge, Polity Press.

Bellow, S. (2016) El legado de Humbolt. Barcelona, Galaxia Gutenberg.

Berger, P. (2014) The many altars of modernity. Alemania, Walter De Gruyter.

Bernal, A. (2009) Cibermundo y educación. Bosquejo de un nuevo marco formativo en contextos postmodernos. Teoría de la Educación, 21 (1), 71-102.

Blom, P. (2010) Años de vértigo. Cultura y cambio en Occidente, 1900-1914. Barcelona, Anagrama.

BuRnetT, J.; MEPhan, T. y Rawson, M. (2000) La aproximación Waldorf-Steiner. En Richter, T. Plan de estudios de la pedagogía Waldorf-Steiner. Madrid, Editorial Rudolf Steiner, 33-40.

CAMPillo, A. (1985) Adiós alprogreso. Una meditación sobre la Historia. Barcelona, Anagrama.

Cejudo, R.; Montero, M. del M. y Ruiz, J. C. (2011) Sobre la cultura hipermoderna: entrevista a Gilles Lipovetsky. Ámbitos, Revista de Estudios de Ciencias Sociales y Humanidades, 26, 13-17.

Club DE Roma (1972) The limits to growth. Consultado el 3 de octubre de 2016. http://www. clubofrome.org/report/the-limits-to-growth/.

Collom, E. (2005) The Ins and Outs of Homeschooling: the Determinants Parental Motivations and Students Achievements. Education and Urban Society, 37, 307-335. doi: $10.1177 / 0013124504274190$.

Cuesta, R. (2009) Sociogénesis de una disciplina escolar: la historia. Barcelona, Pomares-Corredor.

Freunde DER ERZIEHUNGSKUNST Rudolf STEINERS (2016) Waldorf Worldwide List. Consultado el 1 de septiembre de 2016. https://www.freunde-waldorf.de/fileadmin/user_upload/ images/Waldorf_World_List/Waldorf_World_List.pdf.

Goodman, P. (1970) La Comunidad de los estudiantes. Una desafiante crítica a la estructura actual de la educación. Buenos Aires. Proyección.

Gosálvez, P. (2015) Los jesuitas revolucionan el aula. El País. 25/03/2015. Consultado el 7 de noviembre de 2016. http://politica.elpais.com/politica/2015/03/27/actualidad/1427473093_128987.html.

Greene, M. (1994) Postmodernism and the Crisis of Representation. English Education, 26 (4), pp. 206-219.

Holt, J. (1977) El fracaso de la escuela. Madrid, Alianza Editorial.

IgELMO, J. (2015) Teoría e Historia de una respuesta subalterna a la pedagogización: el movimiento unschooling. Temps d'Educació, 48, 51-69.

IGELMO, J. y LAUDO, X. (2017) Las teorías de la desescolarización y su continuidad en la pedagogía líquida. Educación XXI, 20 (1). 37-56. doi: 10.5944/educXX1.11465.

Illich, I. (1971) Deschooling Society. Nueva York, Harper and Row.

LACHMAN, G. (2007) Rudolf Steiner. Girona, Atalanta. 
LAUDO, X. (2011) La hipótesis de la pedagogía postmoderna: educación, verdad y relativismo. Teoría de la Educación, 23 (2), 45-68.

Lipovetsky, G. (1986) La era del vacío. Barcelona, Anagrama.

Lipovetsky, G. (2016) De la ligereza. Barcelona, Anagrama.

Lipovetsky, G. y Charles, S. (2006) Los tiempos hipermodernos. Barcelona, Anagrama.

Lizcano, E. (2006) Metáforas que nos piensan. Sobre ciencia, democracia y otras poderosas ficciones. Madrid, Bajo Cero y Traficantes de Sueños.

LyOTARD, J. F. (1994) La condición postmoderna. Madrid, Cátedra.

MarshaK, D. (1997) The common vision. Parenting and educating for wholeness. United States of America, Peter Lang.

Mayberry, M. (1988) Characteristics and attitudes of families who homeschool. Education and Urban Society, 21 (1), 32-41. doi: 10.1177/0013124588021001004.

Mcluhan, M. (1974) El aula sin muros, en CARPENTER, E. y MCluhan, M. El aula sin muros. Barcelona, Laia, 235-238.

Meadows, D. H.; Meadows, D. L.; Randers, J. y Behrens, W. W. (1972) The Limits to Growth. A Report Fort he Club of Rome's Project on The Predicament of Mankind. Nueva York, Universe Books.

Moret, R. (2012) La posmodernidad: intento de aproximación desde la Historia del pensamiento. Bajo Palabra, 7, 339-348

OCHOA DE LA FuENTE, L. (2015) Creer, poder y hacer. Horizonte 2020 en las escuelas jesuitas de Barcelona. Propuesta Educativa, 44 (2), 38-53.

PÉrez de AyAla, R. (1983) A.M.G.D. Madrid, Cátedra.

Prats, E.; NúÑEz, L.; Villamor, P. y Longueira, S. (2016) Pedagogías emergentes: una mirada crítica para una formación democrática del profesorado, en CARRILLO FLORES, I. (coord.) Democracia y educación en la formación docente. Barcelona, Servei de Publications de la Universitat de Vic-Universitat Central de Catalunya, 21-48.

Quiroga, P. (2015) La recepción de la pedagogía Waldorf en España. Tesis doctoral. Universidad Complutense de Madrid.

Quiroga, P. y Girard, O. (2015) La expansión internacional de la pedagogía Waldorf: un análisis histórico. Temps d'educació, 48, 91-109.

Quiroga, P. e Igelmo, J. (2013) La pedagogía Waldorf y el juego en el jardín de infancia: una propuesta teórica singular. Bordón, 56 (1), 79-92.

RAwSOn, M. (2010) Sustainable teacher learning in Waldorf education: a social-cultural perspective. Research on Steiner Education, 1 (2), 26-42.

Rawson, M.; PODirsky, K.; Richter, T. y SCHIRMer, H. (2000) Un currículo horizontal, en Richter, T. Plan de estudios de la pedagogía Waldorf-Steiner. Madrid, Editorial Rudolf Steiner, 69-90.

Sanmartín, O. (2015) Así se enseña sin asignaturas, sin libros de texto y sin exámenes. $E l$ Mundo, 16/04/2015. Consultado el 7 de noviembre de 2016. http://www.elmundo.es/ espana/2015/04/16/552eb3c9e2704e972c8b4578.html.

SAURA, G. y LuENGO, J. (2015) Biopolítica y educación. Medición, estandarización, regulación poblacional. Teoría de la Educación, 27 (2), 115-135. doi: http://dx.doi.org/10.14201/ teoredu2015272115135.

SCHIEREN, J. (2012) The concept of learning in Waldorf education. Research on Steiner Education, 3 (1), 63-74. 
Sotés, M. A.; URPí, C. y Molinos, M. del C. (2012) Diversidad, participación y calidad educativas: necesidades y posibilidades del Homeschooling. Estudios sobre Educación, 22, 55-72.

SteIner, R. (1914) Anthroposophy and Christianity. Consultado el 2 de septiembre de 2016. http://wn.rsarchive.org/Lectures/AntChr_index.html.

SteIneR, R. (1923) Andar, hablar y pensar, en BerLIn, J. (rec.) (2013) El primer septenio. La educación preescolar según las enseñanzas de Rudolf Steiner. Madrid, Editorial Rudolf Steiner, 13-26.

SteIner, R. (1973) Anthroposophical Leading Thoughts. Consultado el 1 de noviembre de 2016. http://wn.rsarchive.org/Books/GA026/English/RSP1973/GA026_index.html.

STEINER, R. (2014) El estudio del hombre como base de la pedagogía. Madrid, Editorial Rudolf Steiner.

TAYLOR, C. (2002) Modern Social Imaginaries. Public Culture, 14 (1), 91-124.

TAYlor, C. (2007) A secular age. Cambridge and London, The Belknap Press of Harvard University Press.

Trilla, J. (2005) Hacer pedagogía hoy, en Ruiz Berrio, J. (ed.) Pedagogía y educación ante el siglo XXI. Madrid, Universidad Complutense de Madrid, 287-309.

TRÖHLER, D. (2013) Los lenguajes de la educación. Los legados protestantes en la pedagogización del mundo, las identidades nacionales y las aspiraciones globales. Barcelona, Octaedro.

u.s. Department of Education-Office of Non-Public Education (onpe) (2016) Statistics About Nonpublic Education in the United States. Consultado 21 de octubre de 2016. http://www2.ed.gov/about/offices/list/oii/nonpublic/statistics.html.

VAN MANEN, M. (2015) El tacto en la enseñanza. El significado de la sensibilidad pedagógica. Barcelona, Paidós.

VAtTimo, G. (1985) El fin de la modernidad. Nibilismo y hermeneútica en la cultura posmoderna. Barcelona, Gedisa.

Verger, A. y Bonal, X. (2009) Resistance to the Gats, en Hill, D. (ed.) Contesting Neoliberal Education. Public Resistance an Collective Advance. Nueva York, Routledge, 181-201. 